\title{
Die Europäische Gemeinschaft und die Konventionen des einheitlichen Privatrechts
}

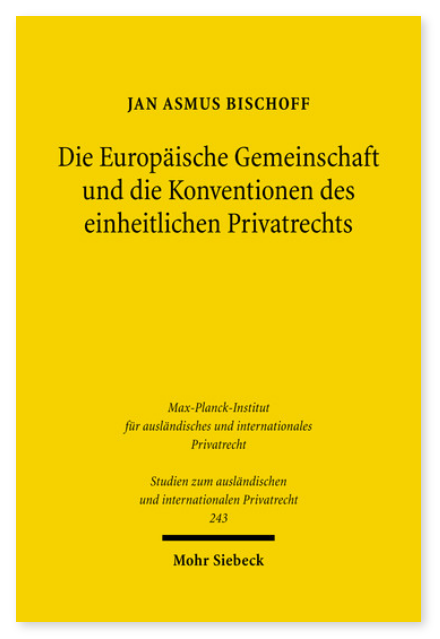

2010. XXVII, 465 Seiten. StudIPR 243

ISBN 978-3-16-151428-9

DOI 10.1628/978-3-16-151428-9

eBook PDF 104,00€

ISBN 978-3-16-150309-2

fadengeheftete Broschur 104,00€
Die verstärkte Vereinheitlichung des Privatrechts auf europäischer Ebene ruft nach einer Klärung des Verhältnisses des Gemeinschaftsprivatrechts zu der klassischen Privatrechtsvereinheitlichung durch völkerrechtliche Verträge. Jan Asmus Bischoff vergleicht die unterschiedlichen Entwicklungen des Einheitsprivatrechts und des Gemeinschaftsprivatrechts, um die möglichen Konfliktlagen, aber auch die möglichen Synergien aufzuzeigen. Er analysiert die Rechtswirkungen der einheitsrechtlichen Konventionen der Gemeinschaft selbst, aber auch der Mitgliedstaaten für den Gemeinschaftsgesetzgeber und die Gemeinschaftsgerichtsbarkeit. Schließlich zeigt er auf, dass durch die derzeitige Behandlung der Gemeinschaft durch das Konventionsprivatrecht und durch die Kompetenzverteilung zwischen Gemeinschaft und Mitgliedstaaten, Konflikte begünstigt werden, die die Rechtssicherheit gefährden.

Jan Asmus Bischoff Geboren 1980; Studium der Rechtswissenschaft in Hamburg und New York; 2009 Promotion; derzeit Referendar am Hanseatischen Oberlandesgericht.
Jetzt bestellen:

https://mohrsiebeck.com/buch/die-europaeische-gemeinschaft-und-die-konventionen-des-einheitlichen-privatrechts9783161514289?no_cache $=1$

order@mohrsiebeck.com

Telefon: +49 (0)7071-923-17

Telefax: +49 (0)7071-51104 